Article

\title{
Sustainability of Water Safety Plans Developed in Sub-Saharan Africa
}

\section{Luca Rondi ${ }^{1}$, Sabrina Sorlini ${ }^{1, *}$ and Maria Cristina Collivignarelli ${ }^{2}$}

1 CeTAmb LAB - Research laboratory on Appropriate Technologies for Environmental Management in resource-limited Countries, Department of Civil Engineering, Architecture, Land, Environment and of Mathematics, University of Brescia, Via Branze 43, Brescia 25123, Italy;

E-Mail: 1.rondi@unibs.it

2 DICAr - Department of Civil Engineering and Architecture, University of Pavia, Via Ferrata 3, Pavia 27100, Italy; E-Mail: mcristina.collivignarelli@unipv.it

* Author to whom correspondence should be addressed; E-Mail: sabrina.sorlini@unibs.it; Tel.: +39-030-371-1299; Fax: +39-030-371-1312.

Academic Editor: Marc A. Rosen

Received: 15 May 2015 / Accepted: 5 August 2015 / Published: 14 August 2015

\begin{abstract}
In developing countries, the drinking water supply is still an open issue. In sub-Saharan Africa, only $68 \%$ of the population has access to improved sources of drinking water. Moreover, some regions are affected by geogenic contaminants (e.g., fluoride and arsenic) and the lack of access to sanitation facilities and hygiene practices causes high microbiological contamination of drinking water in the supply chain. The Water Safety Plan (WSP) approach introduced by the World Health Organisation (WHO) in 2004 is now under development in several developing countries in order to face up to these issues. The WSP approach was elaborated within two cooperation projects implemented in rural areas of Burkina Faso and Senegal by two Italian NGOs (Non-Governmental Organisations). In order to evaluate its sustainability, a questionnaire based on five different sustainability elements and a cost and time consumption evaluation were carried out and applied in both the case studies. Results demonstrated that the questionnaire can provide a useful and interesting overview regarding the sustainability of the WSP; however, further surveys in the field are recommended for gathering more information. Time and costs related to the WSP elaboration, implementation, and management were demonstrated not to be negligible and above all strongly dependent on water quality and the water supply system complexity.
\end{abstract}


Keywords: sustainability; Water Safety Plan; drinking water; Senegal; Burkina Faso

\section{Introduction}

In 2000 the member States of the United Nations signed the so-called Millennium Declaration, which later gave rise to eight Millennium Development Goals (MDGs). In particular, Goal 7, to ensure environmental sustainability, included a target $(7 \mathrm{c})$ that challenged the global community to halve the proportion of people without sustainable access to safe drinking water and basic sanitation by 2015 . The WHO/UNICEF Joint Monitoring Programme for Water Supply and Sanitation (JMP) has provided regular estimates of progress towards the MDG targets. According to the last update (2015), the worldwide drinking water coverage relying on improved sources is $91 \%$ (3\% above the MDG target). Thus, 663 million people still relied on unimproved or surface drinking water sources [1].

The worst situation is highlighted to be in the sub-Saharan Africa. Indeed, only $68 \%$ of the population has access to improved drinking water sources, with a strong disparity between urban $(87 \%)$ and rural $(56 \%)$ areas. Even worse the access to improved sanitation facilities reaches only $30 \%$ of the people: The percentage increases up to $40 \%$ in urban areas, whilst it decreases to $23 \%$ in rural areas [1].

In addition to this, it has to be considered that an uncountable number of people, whilst having access to an improved source, consumes drinking water of poor quality due to the lack of proper handling and hygiene during transport and storage steps.

For these reasons, the enactment of the Water Safety Plan (WSP) methodology should be considered in order to prevent (or at least minimise) drinking water contamination, without excluding the enhancement of proper hygiene and sanitation practices. The WSP approach, proposed in the third edition of the World Health Organisation (WHO) Guidelines for Drinking Water Quality (GDWQ) in 2004, in fact, entails the comprehensive assessment of both the risk to health and risk management. This assessment should encompass all stages of the water supply system, from the catchment to the consumer, considering hazards within the system by means of a multi-barrier framework [2].

The previous concentration-based approach, still spread worldwide and only able to determine whether drinking water complied with quality standards, has been overcome with the risk-based approach of the WSP strategy. Indeed, this latter approach can be considered proactive, since it is able to prevent drinking water contamination by means of the identification of all possible hazardous events, other hazards, and the evaluation of the risks related to the drinking water contamination. On the contrary, the previous concentration-based approach is characterised not by its preventative strategy; indeed, within this approach, water contamination is only detected, but not prevented or avoided. Moreover, the new approach takes into account parameters such as the level and duration of exposure to contaminants, their toxicity, and the severity of the diseases they produce in assessing the need for mitigation [3].

Despite several decades of development aid and thousands of international cooperation projects implemented all over the world, the worldwide situation in terms of safe drinking water consumption remains critical, as stated above. A coherent focus on sustainability should be therefore the key 
element for guaranteeing that interventions made by cooperation projects can reach the objectives stated by the MDGs, at least in relation to water supply and sanitation.

Sustainable development is defined as development that meets the needs of the present without compromising the ability of future generations to meet their own needs [4-8]. In order to evaluate and sustain water and sanitation supplies in developing countries, the international literature offers some proposals such as (i) create a "sustainability chain", consisting of motivation, maintenance, cost recovery and continuing support elements [9]; (ii) divide water and sanitation projects into sequential steps [10]; (iii) base the project on three sustainability components: Effective community demand, local financing and cost recovery, dynamic operation and maintenance [11].

Moreover, it should be considered that sustainability is generally higher when the demand is directly expressed by household members and not through traditional leaders or community representatives such as water committees or local governments [12-14]. Therefore to achieve sustainability, water supply and sanitation development requires effective complementary inputs such as community participation, community capacity development, and community training.

This paper aims at presenting two complementary methodologies that can be used in order to evaluate the sustainability of Water Safety Plans (WSPs): The use of a questionnaire is based on five different sustainability elements, to be addressed to the main stakeholders involved in the WSP strategy development, and a cost and time consuming evaluation. These sustainability assessment tools were applied after the WSP approach implementation in rural areas of Senegal and Burkina Faso. The application of these tools permitted the evaluation of their usefulness in assessing the sustainability of rural water services where a WSP approach was applied.

\section{Materials and Methods}

\subsection{The Development of a Simplified Water Safety Plan Approach}

The WSP developed in rural areas of Senegal and Burkina Faso was simplified compared to the original framework proposed by WHO, in order to ensure its suitability and sustainability. Indeed, local conditions are such as the absence of strong institutional support and the low technical expertise of the managers of water supplies and users required to revise and simplify the original approach. Table 1 lists all the steps defined by the WSP framework and highlights $(\checkmark)$ those that were developed in the present research.

Even if the establishment of a qualified and dedicated team is one of the prerequisites of the WSP approach, local conditions did not permit this first step in the Burkina Faso's case study to be rigorously carried out. Thus, the WSP team was composed of users and water committee members, who were the leading subjects involved in the drinking water management along the supply chain.

An aspect that differed from the original framework, for both case studies, was the determination and validation of existing control measures for risk reassessment and prioritisation. This step was not carried out since the already planned control measures for preventing or at least minimising drinking water contamination were not in place. Moreover, a prioritisation of the risks (with a cut-off score under which the causes of contamination can be neglected) was not carried out, as it was considered significantly important to assess and provide control measures for each possible cause of contamination 
(as an effective barrier approach). The reason is that even low minimisation or prevention of contamination can improve the quality of drinking water, and therefore the potential improvement of health conditions of the local population.

Table 1. Steps defined by the Water Safety Plan (WSP) framework.

\begin{tabular}{cc} 
WSP Step & Developed \\
Assemble the WSP team & $\checkmark$ \\
Describe the water supply system & $\checkmark$ \\
Identify hazards and hazardous events and assess the risks & $\checkmark$ \\
Determine and validate control measures, reassess and prioritize the risks & $\times$ \\
Develop, implement and maintain an improvement/upgrade plan & $\checkmark$ \\
Define monitoring of the control measures & $\checkmark$ \\
Verify the effectiveness of the WSP & $\checkmark$ \\
Prepare management procedures & $\times$ \\
Develop supporting programmes & $\checkmark$ \\
Plan and carry out periodic review of the WSP & $\checkmark$ \\
Revise the WSP following an incident & $\times$ \\
\hline
\end{tabular}

In the Burkina Faso case study, since the WSP was elaborated as a prevention tool to be managed by the users, who had no technical expertise in the field, the step related to the verification monitoring programme was not fully developed, thus simplifying the approach. The development of the WSP effectiveness evaluation programme is scheduled to be concluded later.

The technical and organisational conditions in which the WSP was elaborated and implemented in both the rural areas of Burkina Faso and Senegal did not permit the development of management procedures in the conventional way. However, the actions provided within the operational monitoring (monitoring of the control measures, establishment of critical limits and related corrective measures) were developed in order to guarantee their effectiveness.

Finally, for the same reasons stated above, the last step suggested by WHO (the revision of the Plan following every emergency, incident or unforeseen event) was not carried out.

\subsection{Development of a Tool Based on Five Sustainability Elements}

In order to evaluate the sustainability of a water service, several frameworks have already been developed and adopted worldwide, using specific and objective sustainability indices [15-17]. Interesting tools were also suggested by the IRC (International Water and Sanitation Centre) [18,19], where for instance the quality and quantity of water delivered, the distance/access to and reliability of water supply services were the main aspects taken into consideration. Despite this, a new tool was developed for evaluating the WSP sustainability, since it is simpler, easier to carry out and it allows feedback from the stakeholders involved in the project to be quickly obtained. Indeed, these characteristics are considered essential for rural contexts, above all if the stakeholders involved in the sustainability evaluation have not a high educational level and technical expertise.

The tool elaborated in the present research is based on the main five sustainability elements [20-24], and was previously adopted by Zurbrügg et al. [25] in a research concerning the sustainability evaluation of waste management projects. The five sustainability elements are related to: (i) technical 
sustainability, in terms of use of local material and human resources, and appropriate technologies with an affordable and simple operation and maintenance need; (ii) economic sustainability, which means the adoption of technologies or facilities with low costs of investment and operation, able to create local trade and business opportunities, thus guaranteeing a self-reliance; (iii) organisational and institutional sustainability, in terms of acceptance by the local institutions (from the lowest to the highest) and in terms of creating a strong partnership amongst local stakeholders (with a key-role of local NGOs/Associations), able to guarantee that the activities/good practices spread during the project implementation can be carried on even after its "official" end; (iv) social and cultural sustainability, which means developing projects and implementing technologies really felt by the local people that can rapidly show an improvement in everyday life; and (v) environmental and health sustainability, in terms of minimising the use of natural resources by acting on the reuse or recovery of waste or other resources and in terms of confining environmental impacts.

The sustainability concept clearly requires a long-term view of the facility/technology/approach implemented or the behaviour change in the lifestyle generated by the project. On the basis of the elements above mentioned, both the Senegal and Burkina Faso case studies were evaluated at the end of the project implementation.

For each of the five sustainability elements identified, a series of questions was listed and addressed to the main stakeholders of the projects (NGOs, local Authorities, beneficiaries, etc.). The aim of this methodology was to gather specific information about all the likely reasons of success or failure of the projects, and in particular of the WSPs. Table 2 reports, for each sustainability element, the questions provided, which were selected from a longer list of questions initially considered. The choice of the final questions was made based on the two following aspects: (i) the questionnaire should be pithy and easy to carry out since it is addressed also to the population of rural areas (maybe without a certain educational level and technical expertise); and (ii) the questions should consider the most crucial aspects characterising the rural water services.

Table 2. Sustainability elements and related questions.

\begin{tabular}{ll}
$\begin{array}{c}\text { Sustainability } \\
\text { Element }\end{array}$ & Question \\
\hline & Are there locally knowledge and technical expertise necessary for the elaboration and \\
development of a WSP? & Are there locally knowledge and technical expertise necessary for the management \\
& and update of a WSP? \\
& Are there locally knowledge and technical expertise necessary for the design and \\
& construction of a technology for drinking water treatment? \\
& Are there locally knowledge and technical expertise necessary for the operation \\
& and maintenance of a technology for drinking water treatment? \\
& Is there locally the availability of people and material resources for the WSP implementation? \\
& Is there locally the availability of people and material resources for the construction and \\
& management of the technology used for drinking water treatment? \\
& Is the WSP performing as it was designed to perform? \\
& Is the technology used for drinking water treatment performing as it was designed to perform?
\end{tabular}


Table 2. Cont.

\begin{tabular}{|c|c|}
\hline $\begin{array}{c}\text { Sustainability } \\
\text { Element }\end{array}$ & Question \\
\hline Economic & $\begin{array}{l}\text { Is there locally economic availability necessary for the elaboration and development of a WSP? } \\
\text { Is there locally economic availability necessary for the design and } \\
\text { construction of a technology for drinking water treatment? } \\
\text { Is there locally economic availability necessary for the management and update of a WSP? } \\
\text { Is there locally economic availability necessary for the operation and } \\
\text { maintenance of a technology for drinking water treatment? }\end{array}$ \\
\hline $\begin{array}{c}\text { Organisational } \\
\text { and Institutional }\end{array}$ & $\begin{array}{l}\text { Has the WSP team been adequately trained for the implementation and management of the WSP? } \\
\text { Have the managers and operators been adequately trained for the construction, } \\
\text { operation and maintenance of the technology used for drinking water treatment? } \\
\text { Are the WSP managers supported by the local community? } \\
\text { Are the adopted technology managers supported by the local community? } \\
\text { Are the WSP managers supported by the local Institutions (political and technical Institutions)? } \\
\text { Are the adopted technology managers supported by the local Institutions } \\
\text { (political and technical Institutions)? }\end{array}$ \\
\hline $\begin{array}{l}\text { Social and } \\
\text { Cultural }\end{array}$ & $\begin{array}{l}\text { Has the community been informed about the WSP implementation and its benefits? } \\
\text { Has the community been informed about the technology used for drinking water treatment } \\
\text { and its benefits? } \\
\text { Is the community favourable to the WSP implementation? } \\
\text { Is the community favourable to the use of a technology for drinking water treatment? } \\
\text { Does the community contribute and encourage the WSP elaboration and implementation? } \\
\text { Does the community contribute and encourage the use of the } \\
\text { technology for drinking water treatment? }\end{array}$ \\
\hline $\begin{array}{l}\text { Environmental } \\
\text { and Health }\end{array}$ & $\begin{array}{l}\text { Has the WSP implementation improved local people health? } \\
\text { Has the WSP implementation permitted to guarantee the drinking water } \\
\text { quality according to the WHO standards? } \\
\text { Are the adopted technology managers well equipped to assure well-being and health? } \\
\text { Have adequate measures been adopted in order to safety dispose } \\
\text { of any residues produced by the technology for drinking water treatment? } \\
\text { Has the WSP implementation prevented the arising of any negative impact on the environment? }\end{array}$ \\
\hline
\end{tabular}

Taking as reference the technical sustainability element, questions were intended to analyse the different aspects: ability/capability to elaborate, develop and manage the WSP, as well as the ability/capability to design, construct and manage the treatment technology. These aspects do not point to the same issue, but they were analysed from the same point of view (technical, first, and then economic, institutional and organizational, social and cultural, environmental and health). This approach was applied since sustainability can be guaranteed not only by the ability to elaborate the WSP (or the treatment technology), but also by the capability to manage it.

Moreover, questions were related to the WSP in general and also specifically to the treatment technologies implemented in loco (in Senegal bone char-based filtration and chlorination, whilst in Burkina Faso only chlorination). Indeed, water treatment represents the most important stage, above all in rural areas of sub-Saharan Africa, in order to guarantee the consumption of safe drinking water (thus making effective the treatment technology and consequently the WSP). In addition to this, drinking 
water treatment in rural areas of sub-Saharan Africa is rather at household level than at community level, thus having a possible negative influence on its sustainability, owing to the lack of technical skills or social acceptance, etc. For these reasons, questions related to the treatment technology were added into the questionnaire, in order to specifically evaluate the impact of this element on the sustainability of the entire WSP. In such a way, during the elaboration of the questionnaires, the positive or negative effect of the treatment technology on the sustainability of the entire WSP could be highlighted.

The possible answers to each question were: "absolutely yes", "rather yes", "rather no", "absolutely no" and "not applicable to the project". This latter option was provided in order to make the questionnaire applicable to various projects. Indeed, not all the questions could be pertinent for other case studies. Finally, for each answer, a score between 0 and 1 was attributed, in order to assign a numerical value at the sustainability level. Table 3 reports scores related to each possible answer.

Table 3. Scores assigned at each answer.

\begin{tabular}{cc}
\hline Possible Answer & Score/Sustainability Level \\
\hline Absolutely yes & 1 \\
Rather yes & 0.75 \\
Rather no & 0.25 \\
Absolutely no & 0 \\
Not applicable to the project & Not considered \\
\hline
\end{tabular}

As previously stated, the aim of the questionnaire is to collect information about the sustainability of the WSP from the different points of view of the stakeholders involved in the project implementation. For this reason, results obtained by the elaboration of the questionnaire depend on the subjective opinion of each respondent. The value of the questionnaire is not only the score itself, but rather the discussion of the scores amongst the stakeholders, in order to trigger specific actions to improve the sustainability of the water service. The "Results and Discussion" section proposes a comparison between the scores obtained in the two case studies where the questionnaire was tested. The aim is to highlight the possible reasons of success and failure of the WSP approach applied in different contexts of the sub-Saharan Africa, and not to make a strict comparison amongst the two case studies.

\subsection{The Study Area in Senegal}

A cooperation project was started in 2008 in order to improve drinking water quality in the Rural Community of Patar (RCP), in the Diourbel Region (Senegal), in collaboration with the "G. Tovini" Foundation (Italian NGO), the University of Dakar and the Diourbel Hygiene Authority. In 2011, this first project continued with the elaboration and implementation of the Water Safety Plan (WSP) strategy.

The RCP is divided into 52 villages, counting globally about 15,000 inhabitants, with 12 elementary schools, one high school and five health centres. The water supply system is quite complex; three different drinking water sources are locally available: (i) open dug wells, which are located in all the RCP villages (Figure 1); (ii) protected wells network, serving about 3000 people, which extracts water from a shallow aquifer and serves, through a small distribution system, public taps (Figure 2) and 
(iii) groundwater distribution system, serving about 10,000 inhabitants, which pumps water to public and household taps (Figure 3). This latter type of source was the most used by the population for water supply even if shown to be characterised by concentrations of fluoride exceeding the $1.5 \mathrm{mg} / \mathrm{L}$ Guide Value suggested by WHO [26].

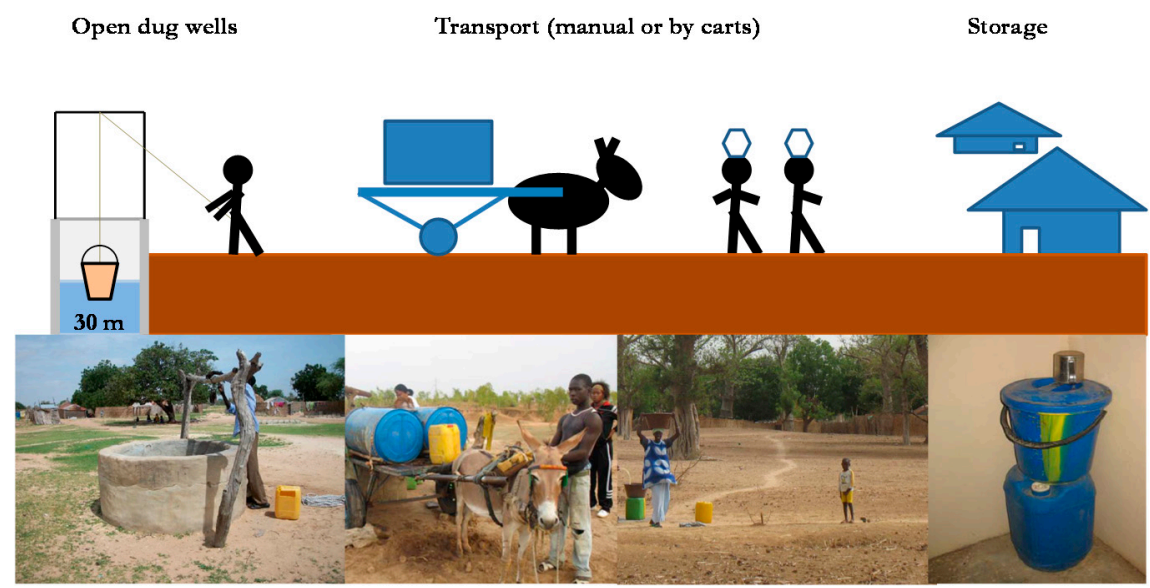

Figure 1. Drinking water supply chains in the Rural Community of Patar (RCP): The open dug wells.

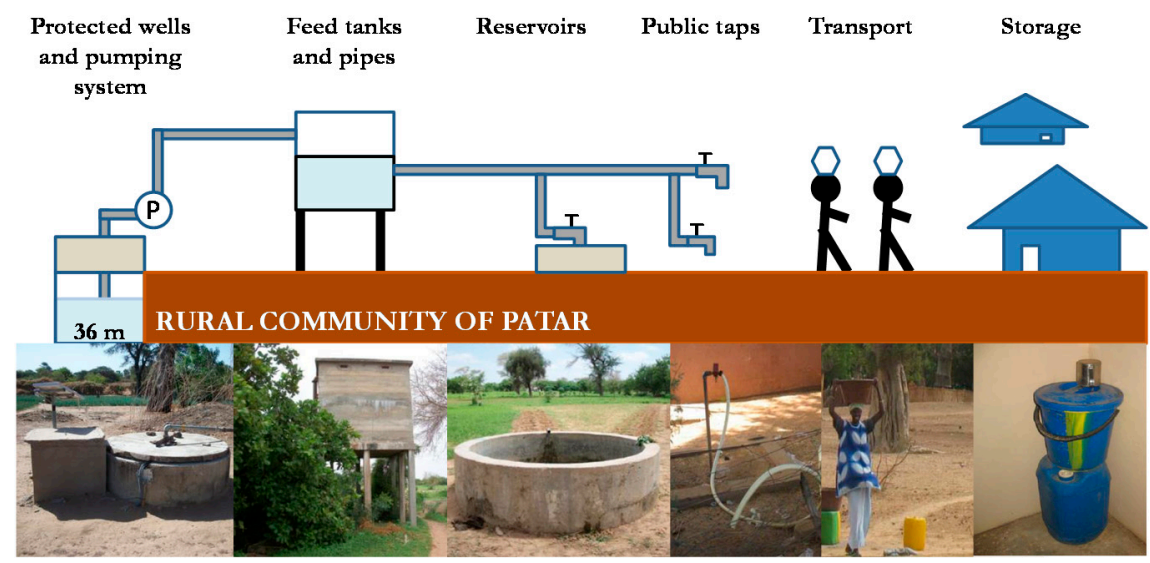

Figure 2. Drinking water supply chains in the RCP: the protected wells network.

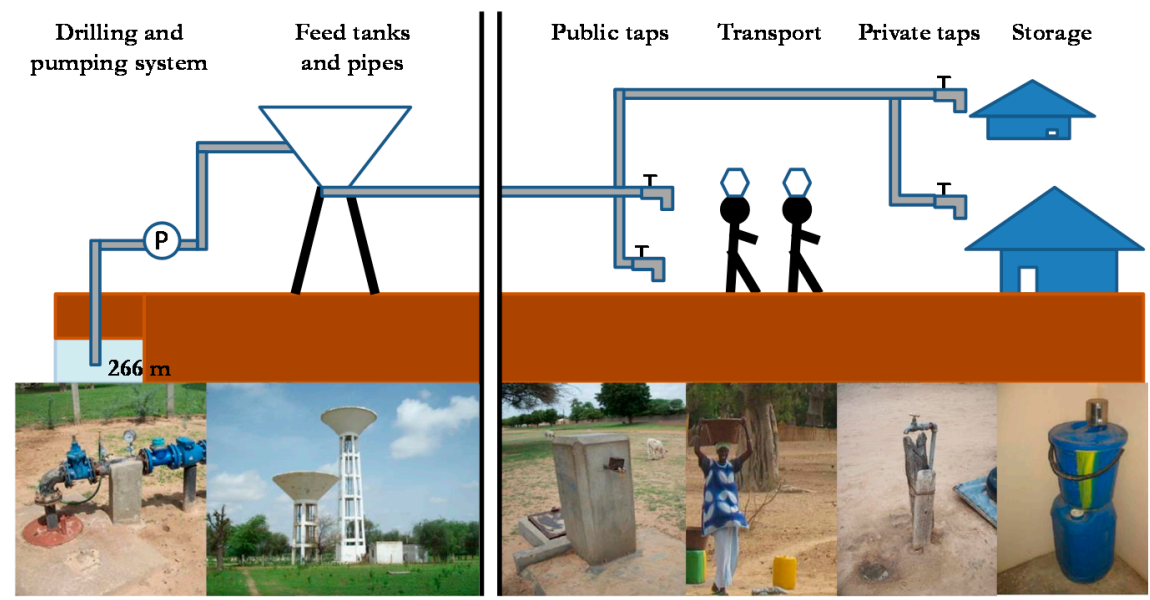

Figure 3. Drinking water supply chains in the RCP: The groundwater distribution system. 
As a response, amongst the activities carried out within the first project, a bone char-based filtration system for fluoride removal was studied, experimented and implemented at household level [27]. In addition to chemical contamination, microbial growth was detected in both the transport and storage tanks, due to a lack of hygiene in handling the containers [28]. For this reason, awareness campaigns for improving hygiene were organised at household level, aimed at enhancing disinfection with chlorine.

The development of the WSP was carried out with the technical support of a technician from the Diourbel Hygiene Authority (DHA) and the manager from ASUFOR (Association responsible for the management of the groundwater distribution system). The WSP team was assembled in order to involve all the organisations responsible for water catchment, distribution and management and in agreement with the Director of DHA and the President of the RCP. The WSP team was composed of 12 people: two representatives of ASUFOR, two representatives of GIE (Association responsible for the management of the protected wells network), two representatives of DHA, the Responsible for the Patar Health Centre (RPHC) and five students of the University of Dakar, who lived in the RCP, as representatives of the community. The WSP team, on one hand, elaborated the WSP and, on the other, was made aware of how to manage and handle drinking water along the entire supply chain in order to prevent or minimise microbiological and chemical contamination.

The sustainability evaluation (questions listed in Table 2) was addressed to the main stakeholders involved into the project implementation: two volunteers of the NGO G. Tovini Foundation (FonTov NGO), who worked directly in the field; four representatives of the local partners, University of Dakar and Diourbel Hygiene Authority (UniDak \& DHA); the WSP team; the most relevant people of the Rural Community of Patar (RCP) involved in the project activities, such as the President of the RCP, the President of the Women Association and the President of the Young People Association.

The choice of these stakeholders "categories" was done in order to collect information from different subjects (each one involved in a different way in the implementation of the project activities) and, hence, to compare different points of view related to the sustainability of the WSP.

\subsection{The Study Area in Burkina Faso}

A cooperation project was started in 2011 in order to improve drinking water quality and health conditions of the population of Fingla and Diarra rural villages (about 3000 people globally), in the Béguédo municipality, Centre-East Region (Burkina Faso). This first project was developed and implemented in collaboration with the NGO Medicus Mundi Italy and the Burkinabè NGO Dakupa.

A preliminary survey conducted in the field enabled highlighting the presence of a simplified drinking water supply chain; indeed, only two main drinking water sources were identified: (i) 16 open dug wells (located only in the village of Fingla) (Figure 4); and (ii) 11 tubewells fitted with hand pumps (located in both the Fingla and Diarra villages), which were the most used by the people for drinking water collection (Figure 5). Despite water quality being acceptable at source level, microbial growth in the transport and storage tanks was detected, revealing a lack of proper handling and hygiene practices. On the contrary, chemical contamination was absent. 


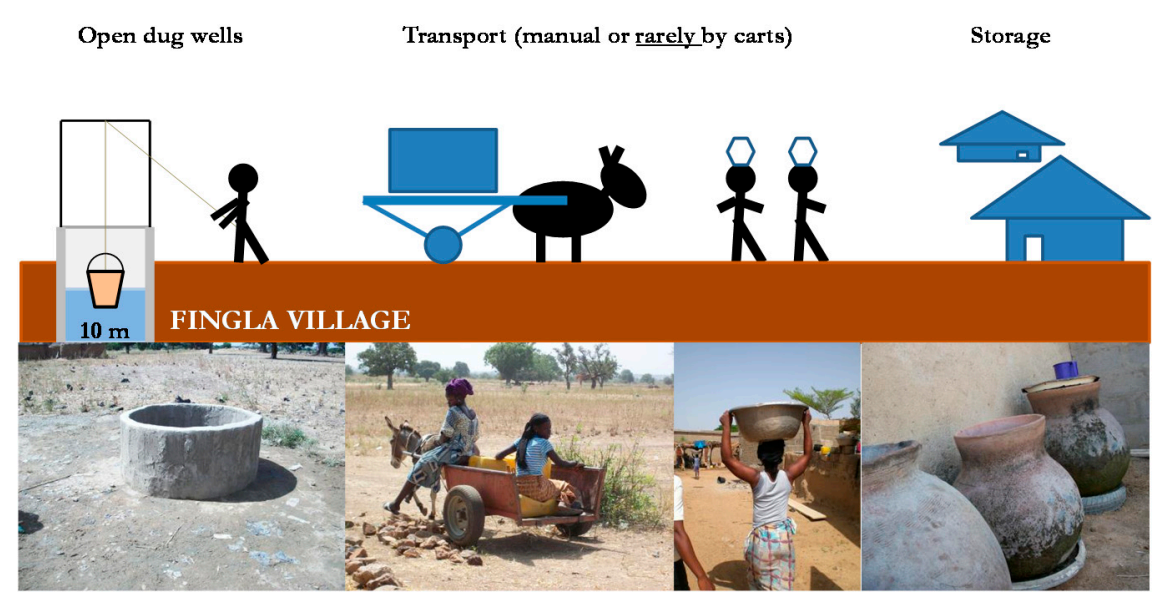

Figure 4. Drinking water supply chains in the villages of Fingla and Diarra: The open dug wells.

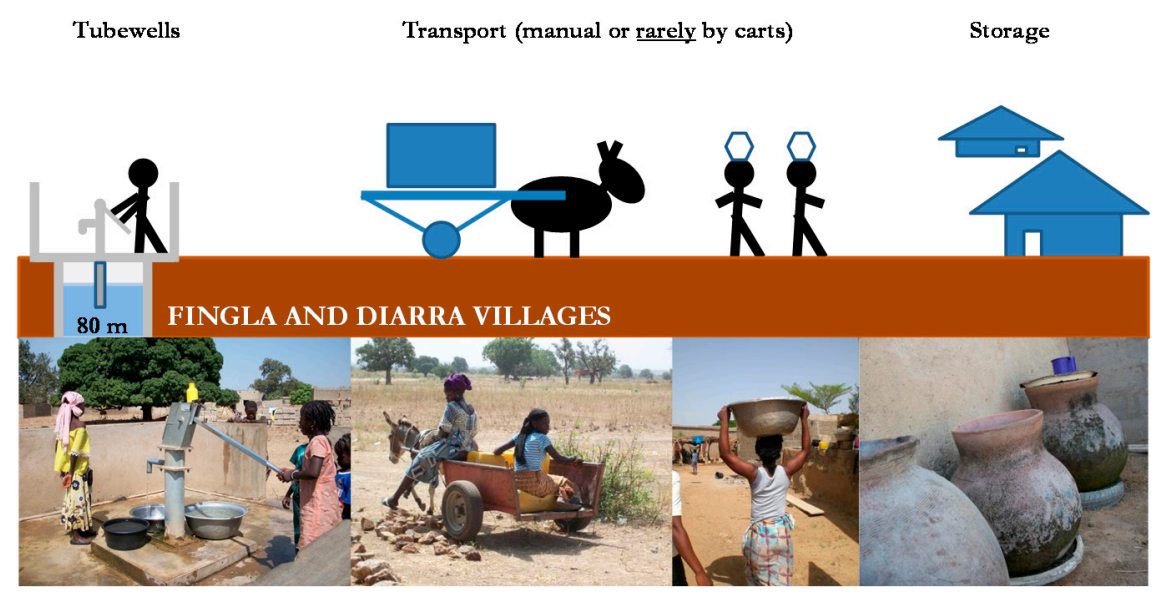

Figure 5. Drinking water supply chains in the villages of Fingla and Diarra: The tubewells fitted with hand pumps.

A specific WSP was developed for each tubewell with hand pump. The people involved in the WSP elaboration (as WSP team) were the water committee (named CGPE) and the source's users. As for the previous case study, the WSP team elaborated the plan and at the same time was made aware of how to manage and handle drinking water along the entire supply chain in order to prevent or minimise contamination.

The sustainability evaluation (questions listed in Table 2) was addressed to the main stakeholders involved into the project implementation: two volunteers of the NGO Medicus Mundi Italy (MMI NGO), who were working in the field for almost the entire period of the project implementation; three representatives of the local NGO Dakupa, responsible for the implementation of the project activities; the team of seven hygienists of Fingla and Diarra villages (Local Hygienists), who had actively worked on the elaboration and implementation of the WSP.

In this case study, the questionnaire was not addressed to the WSP team (composed of the water committees and the users of each tubewell), since this was not officially established. 


\subsection{Complementary Evaluation Based on Costs and Time Consumption}

The WSP implementation requires both financial support and time availability.

The time needed to elaborate a WSP depends on a number of factors. These include the experience of the staff, the amount of data available on the water supply, the size and complexity of the supply, and the presence of potential control systems already adopted. These factors are all inter-related; for this reason, it is difficult to exactly define how much time is required to elaborate a WSP in all circumstances.

Cost is another important factor in the implementation of any new approach or procedure. Risk-based approaches to water safety management, such as the WSP, aim at significantly decreasing costs due to microbial testing. This may offer opportunities for significant savings in countries where consumables for microbial testing are expensive [2]. Thus, financial and resource requirements need to be addressed at the outset, but there should also be the understanding that proper implementation of the WSP approach can save money and better target resources in the longer term [29].

This complementary evaluation of the WSP sustainability was carried out estimating, for both the case studies, costs and times of the three different stages of a WSP approach: Elaboration, implementation, and management. Regarding elaboration, the real amount of money and time spent in loco for the development of each WSP step was considered. Concerning the two other steps, the price of the local resources and materials was considered. Then, costs for the implementation of all the control measures provided by the WSPs were estimated. This was carried out for all the steps of the supply chain: Source, transport, storage and treatment.

\section{Results and Discussion}

\subsection{Appraisal Tool Output}

A comparison between the sustainability evaluation carried out in Senegal and Burkina Faso is proposed in Figure 6. Values provided in the graphs were calculated based on the average score given by each group of stakeholders interviewed; the average sustainability value of each element is also highlighted (yellow boxes). As previously stated, this comparison has only the aim of highlighting the possible reasons of success or failure, without focusing on a strict comparison of the two case studies.

Concerning the technical sustainability, a higher value was obtained in Senegal (77\%) compared to Burkina Faso (73\%), likely owing to the different members characterising the WSP teams. Indeed, in Senegal, the WSP team was composed of the members of the different water suppliers, who had major technical competencies and expertise compared to the inhabitants of Fingla and Diarra villages in Burkina Faso (who represented the WSP team).

Conversely, the economic sustainability element changed strongly in the two different contexts. The high number of significant structural improvements provided by the WSP in Senegal deeply affected this element, which obtained a final average value of $24 \%$. In Burkina Faso, the final average value was equal to $84 \%$, mostly due to the cheapest and easiest actions required by the WSP for preventing water contamination along the supply chain. Indeed, this latter plan was more characterised by behavioural changes than structural improvements. 


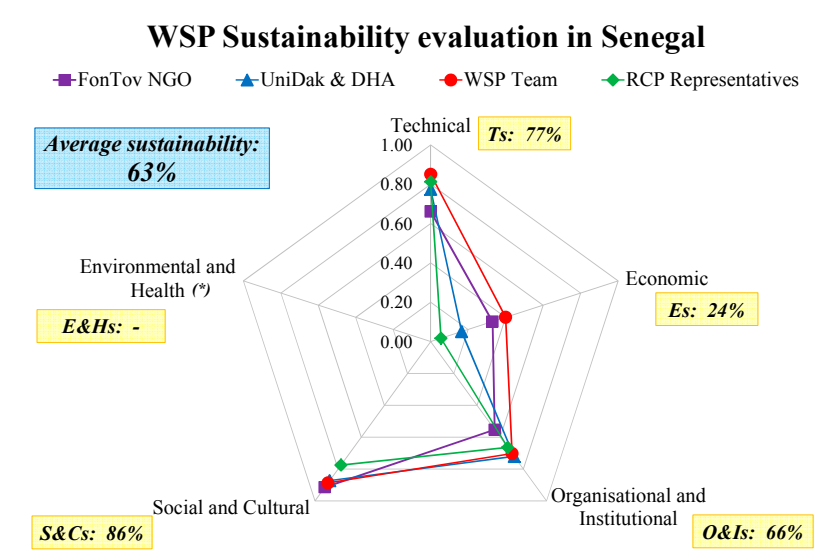

(a)

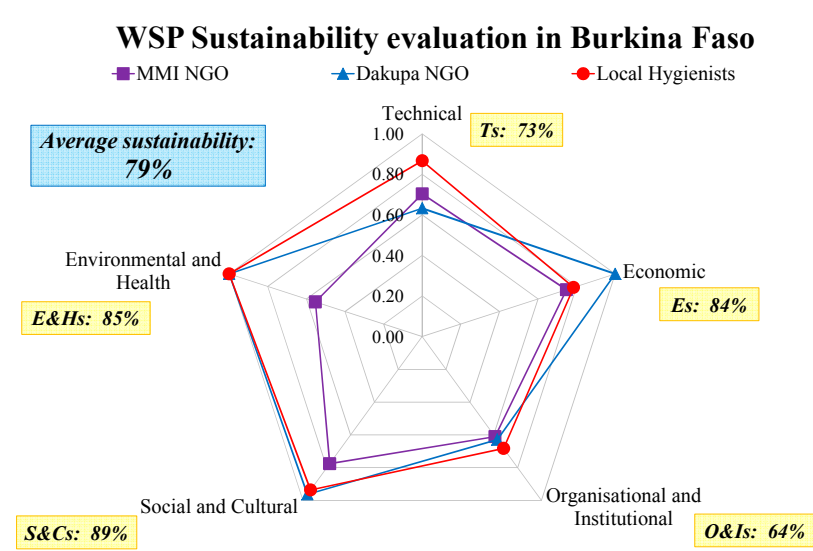

(b)

Figure 6. WSP sustainability's comparison between Senegal (a) and Burkina Faso (b) case studies. ${ }^{(*)}$ : This element was not assessed since the sustainability evaluation was carried out after the first implementation of the WSP approach, when the effects of its adoption could not be assessed.

Regarding the organisational and institutional element, the final average value provided by the Senegal case study was slightly higher (66\%) than in Burkina Faso (64\%). Actually, in both contexts, an important cause of the low sustainability value was the lack of support provided by local institutions, both technical and political.

Values related to the social and cultural sustainability were, as for the previously element, quite similar between them, even if slightly lower in Senegal (86\%) than in Burkina Faso (89\%). In fact, local communities were demonstrated to be participative and to support the WSP elaboration and implementation. Moreover, this element revealed provision of the highest sustainability value amongst the five elements investigated, meaning that socio-cultural support of the population was gained during the project implementation.

Regarding the environmental and health sustainability, comparisons are not possible due to the lack of information related to the Senegal case study. Indeed, questions concerning this element assume that the WSP has already been in place for a certain period of time, in order to verify its impact on the environment and on people's health conditions. In the Senegal case study, the sustainability evaluation was carried out immediately after the implementation of the WSP approach, when the effects on the environment and people's health were not yet appreciable.

The average sustainability values did not considerably differ within each case study, except for the economic element in Senegal and for the environmental and health element in Burkina Faso.

In Senegal, the reason for this difference should be sought from the different roles that each stakeholder played within the project. Indeed, the highest values were assigned by the WSP team and the volunteers of the Italian NGO who have actively supported the elaboration of the WSP, thus recognising the ability of communities to collect the money needed for the implementation of the control measures. Conversely, the lowest sustainability was provided by local partners, who were more involved in the mobilisation of resources for the WSP implementation and management, and, hence, were less sure of the possibility of gaining the amount of money required for the WSP implementation. 
Concerning the environmental and health element in Burkina Faso, the main difference was due to the extremely low judgment provided by the Italian NGO. The discriminating factor was the quality of drinking water (at the transport and storage level) that did not respect the quality standards (second question related to this sustainability element, see Table 2). Despite this, Dakupa NGO and local hygienists assigned positive values to the sustainability level of this element, owing to the decreasing trend obtained by the microbiological analyses of drinking water, along the entire supply chain (some $60 \%, 75 \%$, and $85 \%$ microbial reduction at source, transport and storage level respectively), after the WSP implementation. Indeed, this was considered as a proof that drinking water quality standards could be achieved in a short period of time.

Globally, the WSP developed in Senegal appeared to be less sustainable than the one implemented in Burkina Faso. Indeed, the average sustainability (comprehensive of all the scores assigned by the different stakeholders interviewed, for all the five sustainability elements evaluated) obtained a final value of $63 \%$ and $79 \%$ for Senegal and Burkina Faso respectively (blue boxes of Figure 6).

The comparison of the sustainability evaluation, strictly related to the specific questions concerning treatment technology, is presented in Figure 7.

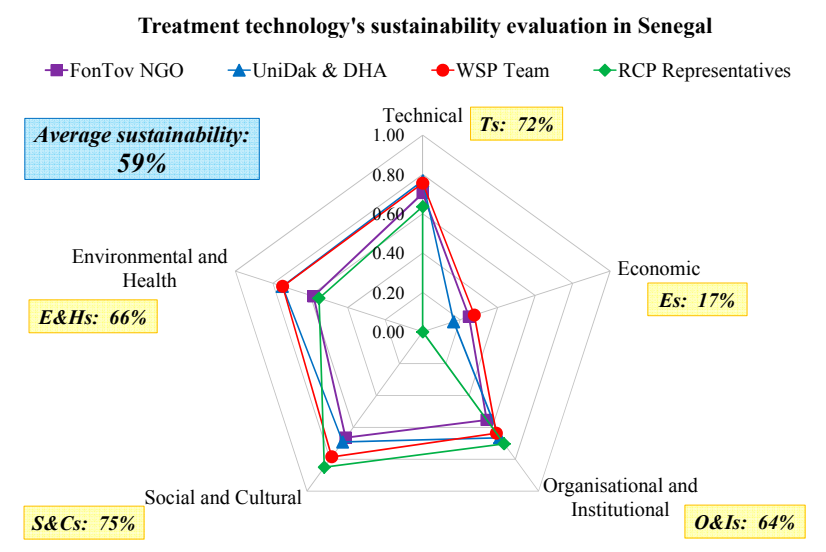

(a)

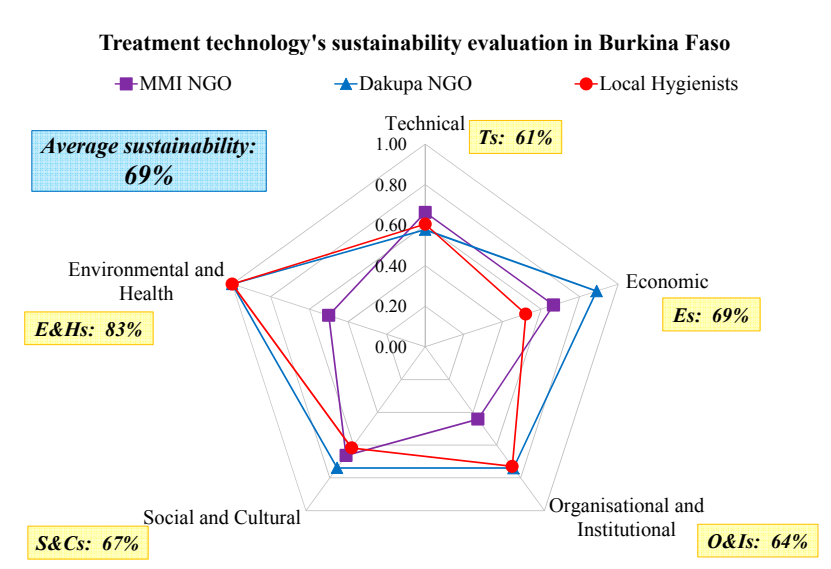

(b)

Figure 7. Treatment technology sustainability's comparison between Senegal (a) and Burkina Faso (b) case studies.

The technical element provided a higher sustainability value in Senegal (72\%) compared to Burkina Faso (61\%), likely due to the poor diffusion of the chlorination treatment amongst the community as well as the use of improved storage containers.

As in the evaluation of the entire WSP sustainability, the economic element was significantly lower in Senegal (17\%) compared to Burkina Faso (69\%), mostly due to the need of a periodic and constant supply of bones in order to guarantee the functioning of bone char-based filters.

Even for the organisational and institutional element, the sustainability value was not very high (64\% in both the case studies), owing to the lack of support by local political and technical institutions.

Concerning the social and cultural sustainability, the survey provided higher results for the Senegal case study (75\%) in comparison with the Burkina Faso one (67\%). In this latter context, the most critical aspect was related to the community acceptance of the chlorination treatment, which had not yet spread amongst the population. The proof that behavioural change is not easy to gain in a short 
period of time was given by a survey conducted after the WSP implementation. Indeed, only few households were highlighted as properly carrying out disinfection with chlorine.

Conversely, regarding the environmental and health element, better results were obtained in Burkina Faso (83\%) than in Senegal (66\%), above all owing to the lack of the safe disposal of exhausted bone chars in the RCP. The absence of residues derived from the water treatment introduced in the Burkina Faso case study strongly contributed to the higher sustainability value.

Globally, the treatment technology developed in Senegal appeared to be less sustainable than the one implemented in Burkina Faso. Indeed, the average sustainability provided a final value of 59\% and $69 \%$ for Senegal and Burkina Faso case studies respectively.

These comparisons highlighted that the treatment technology negatively affected, as expected, the WSP sustainability. In both the case studies, this negative influence was higher for the economic and social and cultural elements.

Moreover, the work carried out in the field highlighted that the support from local partners was completely different in the two case studies: If in Burkina Faso support was constantly provided along elaboration and implementation of the WSP and guaranteed an active development of the supporting programmes, in Senegal local partners did not provide the same support. This is an aspect extremely relevant in order to guarantee sustainability of the activities carried out in both the case studies, as local partners represent the only reference point for local communities after the end of the project implementation. Probably, this different behaviour of local partners influenced the results of this sustainability evaluation, where a higher value was obtained in Burkina Faso.

\subsection{Time and Costs Analysis}

This second sustainability evaluation began with the estimate of the time needed for the development of the WSP in both the case studies. This analysis was carried out only regarding the first two steps of the WSP development (elaboration and implementation), without considering the management that lasts for an unlimited period of time. Figure 8 reports the time needed for the development of WSPs in Senegal and Burkina Faso.

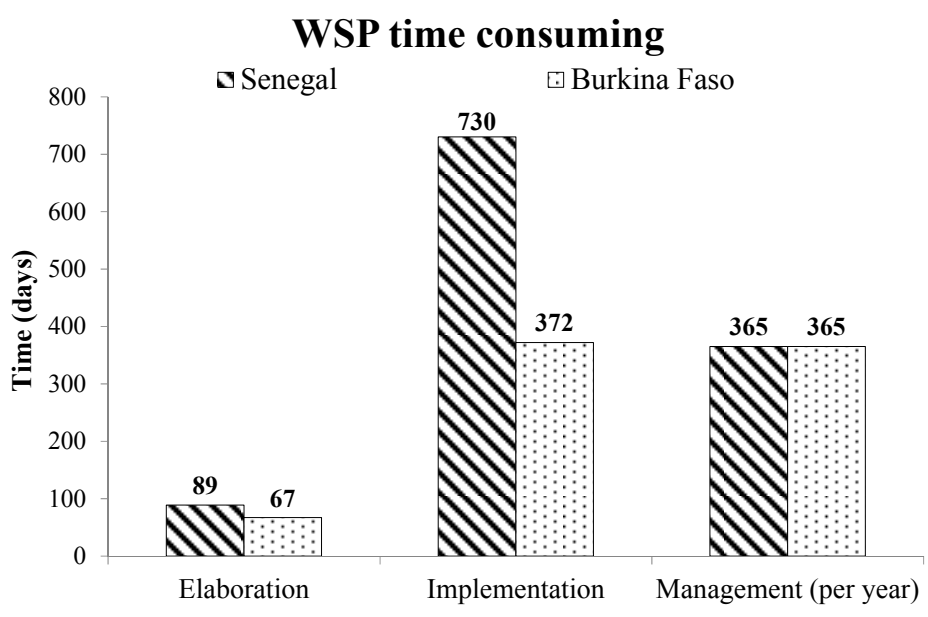

Figure 8. Time required for the elaboration, implementation and management of WSPs in Senegal and Burkina Faso. 
Referring to the elaboration of the WSP, the different steps taken into consideration were: the assembly of the WSP team, the identification of the entire drinking water supply system, the evaluation of all the possible hazards along the supply chain and the elaboration of the plans. Amongst these steps, the hazard assessment represented the most time consuming step. Indeed, this requires the following activities to be carried out: identification of water points with related sanitary inspections and drinking water quality analyses (physical-chemical and microbiological); identification of all the types of vessel employed for transporting and storing water, and related drinking water quality analyses; interviews addressed to water committees and local communities. Considering all these aspects, the time required in Burkina Faso was part of 30 days, whilst in Senegal it was double. The reasons for this difference should be sought in the more complex water system and in the larger and more populated areas to be assessed in Senegal.

Conversely, referring to the implementation of the WSP, the steps considered were: to apply all the control measures provided by the WSPs and to carry out supporting programmes. Even in this comparison, the Senegal case study required more time (730 days were estimated compared to the 372 of the Burkina Faso case study), owing to the higher number of control measures to implement according to the WSP developed.

The cost analysis was carried out for all the three steps of the WSP development (elaboration, implementation, and management). In order to determine the costs, the amount of money required for the implementation of all the control measures provided by each WSP was estimated. This estimation considered the local price of materials and resources, both in Senegal and Burkina Faso. Figure 9 outlines costs of the three different steps of the WSP development. Costs related to the WSP elaboration referred to the risk assessment phase (drinking water quality analyses, interviews, etc.) and to all the activities carried out for the development of the WSP. Costs related to implementation and management phases concerned all the control measures provided for each step of the drinking water supply chain (i.e., source, transport, storage and treatment).

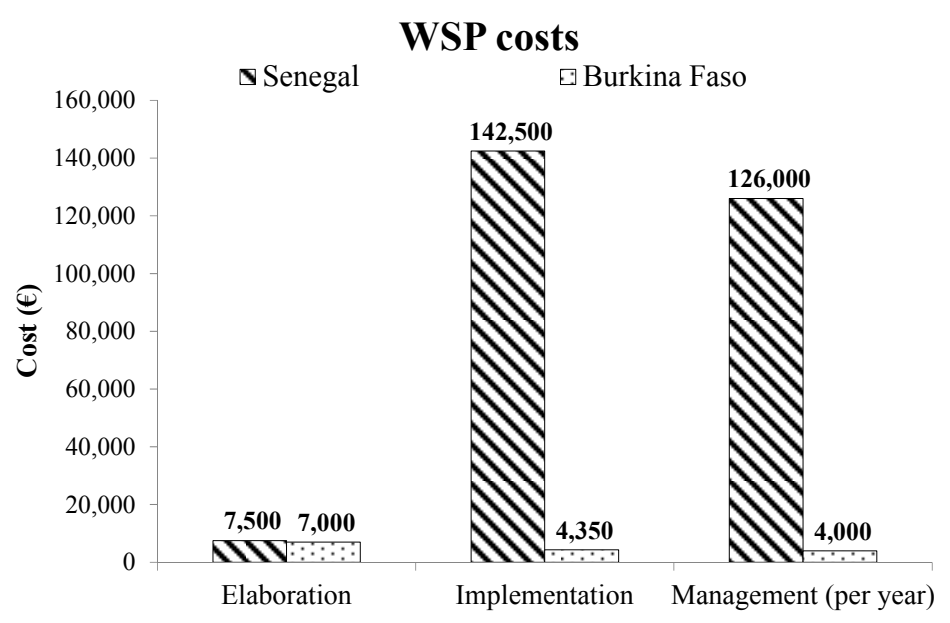

Figure 9. Costs related to the different steps of the WSP development for both case studies.

In Senegal, the most expensive phase was revealed as the implementation (the estimates carried out provided a final value of about $142,500 €$ ), although costs were estimated to be rather high even in the routine management (part of 126,000 €). The reason for this should be sought in the complexity of the 
water supply in Senegal, due to the presence of a groundwater distribution system, a small drinking water network and some of 200 open dug wells. This latter type of source determined the highest costs, owing to the need for building several infrastructural elements (such as slab covers, appropriate parapets, concrete aprons, and drainage channels) for guaranteeing the distribution of safe drinking water. The comparison between the two case studies outlined the activities needed to put in for safety for the different sources of water in the RCP which accounted for about 87,500 $€$, whilst in the Fingla and Diarra villages for part of $1500 €$ (this estimate includes interventions for both the villages). Concerning the water treatment, in Senegal a total amount of about 50,000 $€$ was required, whereas in Burkina Faso part of $500 €$. This huge difference is justified by the need to regularly supply all the approximately $1500 \mathrm{RCP}$ families with bones for the drinking water treatment.

The same considerations can be provided for the management step, where costs were greater in Senegal compared to Burkina Faso, owing to the higher amount of money needed for the drinking water treatment.

This analysis showed that costs were unlikely sustainable for the RCP in Senegal, whereas in the rural villages of Burkina Faso they were more affordable. In order to guarantee the sustainability of the WSPs developed, several alternative solutions able to make feasible the implementation of all the control measures (thus covering all the costs) were analysed. The distribution of all the costs amongst local population appeared to be the most sustainable alternative. Indeed, implementation costs, if homogenously distributed amongst the households of the RCP in Senegal and the Fingla and Diarra villages in Burkina Faso, required that each family contribute a total amount of money equal to $95.00 €$ and $21.75 €$ respectively for the Senegal and Burkina Faso case studies. Considering the average annual revenue of each household in both communities (calculated on the base of the information gathered during the interviews), equal to 1400 and $480 €$ per household in Senegal and Burkina Faso respectively, the amount of money required for the implementation of the WSPs represented $7.0 \%$ and $4.5 \%$ of the average annual revenue respectively. Regarding the management costs, these ratios were estimated to be equal to $6.0 \%$ and $4.0 \%$ respectively.

\section{Further Considerations}

A key element that should be considered for the sustainability evaluation of WSPs is the complexity of the drinking water supply system. Indeed, this experimental research highlighted that the more complex the water system, the more complex the related WSP development is and, hence, the more the time and costs.

In the following, some considerations based on these experiences are provided in order to better clarify which elements can make the elaboration of a WSP complex, above all in rural areas of sub-Saharan Africa. The first element is the number of water points available in loco and used by communities for drinking purposes; indeed, the higher the number of water sources, the higher the costs are due to implementation and management of control measures. Even the complexity of each water point plays a key role; indeed, the more complex the water system (presence of pipe interconnections, tanks, valves, taps, etc.), the more possible the causes of contamination can contribute to drinking water pollution, thus the more the controls should be identified, implemented and managed. Another element to consider is the number of unimproved water points without controls 
already in place, since the complexity of the WSP increases as well as all related costs of implementation, in order to put in safety water points. Complexity of the transport and storage steps should not be underestimated; indeed, similar to the complexity of the water system, the higher the complexity, the more the possible causes of contamination and the more the controls are required (even in a costs and time consuming way). Another factor to take into account is the type of drinking water contamination, since controls required for a drinking water microbiologically contaminated are more related to changes in management behaviour (thus less expensive), compared to the ones necessary to minimise or prevent a chemical contamination (more time consuming and costly). Moreover, the technical competencies and skills of water committees should be taken into consideration: High technical competencies could bring in already adopted controls in order to prevent drinking water contamination (thus minimising global costs), or at least allow the time needed in both WSP elaboration and implementation steps to be minimised.

Finally, even the characteristics of the local context should be carefully considered. Obviously the local context strongly influences the WSP development and consequently its sustainability. The main factors that should be taken into account in this "category" are:

- Number of inhabitants: The greater the community, the more complex (and costly) is the WSP development.

- Social-cultural and political structure: A simple political authorities' structure and a social-cultural availability positively contribute to the WSP sustainability.

- Support of local (technical and political) authorities: WSP more sustainable if support is guaranteed.

- Presence/absence of water committees: Water committees already in place make the WSP development simpler.

- Presence/absence of control measures already in place in order to prevent/minimise drinking water contamination: Controls already in place positively contribute to the WSP sustainability and strongly help to minimise costs and time.

- Drinking water management (use of more or less appropriate practices): The more good practices are spread, the simpler, cheaper and less time consuming (and thus the more sustainable) is the WSP.

\section{Conclusions}

This research aimed at presenting two complementary methodologies for WSP sustainability evaluation, tested in two rural areas of sub-Saharan Africa (Senegal and Burkina Faso).

The first method lies in a series of questions related to five sustainability elements: technical, economic, organisational and institutional, social and cultural, environmental and health. The questionnaire should be addressed to the main stakeholders involved in the WSP development. The tool aims at gathering all the information needed to highlight, according to the opinions of the respondents, all the likely reasons of success or failure related to the sustainability of rural water services in which the WSP approach is applied.

The second method, instead, lies in a time consuming and costs analysis. Based on the three different steps of the WSP development (elaboration, implementation, and management), an estimate 
of time needed and costs to cover should be carried out (based on control measures provided by the WSP), in order to better evaluate the WSP sustainability.

The following highlights summarise the main conclusions of this experimental research:

$\checkmark$ The use of the questionnaire permitted highlighting of the elements able to guarantee the sustainability of the WSP, such as the technical and the social and cultural elements that obtained the highest average scores. Moreover, the possible elements of failure were also outlined, such as the economic one.

$\checkmark$ The questionnaire alone cannot be the only method to investigate the sustainability of a project, but it can provide a general overview from the standpoint of the different stakeholders. Indeed, as shown by the results of the two case studies, the application of the questionnaire alone would not have allowed understanding of some aspects (appreciated thanks to the surveys carried out in loco). One of these is the presence of a strong local partner (as an NGO), able to gain the reliance of the local communities in the project, assuring its sustainability. This positive aspect resulted in a degree of success, due to the investigations conducted in loco.

$\checkmark$ The questionnaire relies on the subjective interpretation of the different stakeholders involved in the sustainability evaluation, as clearly highlighted in the environmental and health element of the Burkina Faso case study.

$\checkmark$ The sustainability evaluation performed by means of the questionnaire was carried out at the end of the projects, but a long-term assessment (after 1, 5, or 10 years) should also be provided in order to deeply understand the projects' effectiveness. Moreover, if revised, the questionnaire can also be useful for evaluation of the sustainability of the activities (technologies or approaches implemented) before and during the project development.

$\checkmark$ Time needed for the development of a WSP is not negligible. The WSP step characterised by the highest time consumption was demonstrated to be hazard assessment (in both the case studies). The WSP implementation, in terms of time, can vary depending on water system complexity.

$\checkmark$ WSP costs were demonstrated to be strongly dependent on water system complexity and drinking water pollution. Indeed, the easy structure of the water supply system and the only presence of microbiological contamination in Burkina Faso provided rather acceptable costs of WSP implementation and management, whilst the more complex and polluted water system in Senegal was related to extremely high costs.

$\checkmark$ An interesting solution for making sustainable costs of the WSP implementation can be to spread them amongst the local community (if feasible), otherwise the need of external funds is mandatory.

$\checkmark \quad$ The time and costs analysis carried out in this research was useful for understanding how the complexity of the water system under investigation should be carefully considered before the WSP elaboration and implementation.

Based on these conclusions, the following recommendations on the use of the tools proposed are provided:

$\checkmark$ Due to the subjective nature of the questionnaire, the final scores should not be considered as absolute values. Indeed, these scores should be used not only to strictly evaluate the 
sustainability of the WSPs, but rather to trigger discussions amongst the stakeholders in order to identify actions able to improve the sustainability of the rural water services.

$\checkmark$ The questionnaire elaborated in the present research could be improved, providing different or more questions, above all in order to investigate the sustainability of the economic, organisational and institutional, and environmental and health elements.

$\checkmark \quad$ If applied in a context where the water treatment does not represent a critical aspect in the supply chain, the specific questions addressed to investigate this phase should be ignored, in order to make the questionnaire pithier.

$\checkmark$ A survey in the field should be carried out before the WSP elaboration, in order to evaluate the presence of a strong local partner able to strengthen the activities/actions recommended by the WSP approach (possible reason of success) and to evaluate the complexity of the water supply system (possible reason of failure, above all in rural areas of sub-Saharan Africa).

$\checkmark$ During the WSP development, the cost analysis should be used to address a list of priority interventions to put in place in order to guarantee (as far as possible in rural areas of sub-Saharan Africa) the safety of the drinking water distributed and consumed, and thus the effectiveness of the WSP.

\section{Acknowledgments}

Luca Rondi conducted this research as PhD student on "Appropriate Methods and Technologies for International Development Cooperation", supported by Alberto Archetti Fund. Authors wish to thank: NGOs Medicus Mundi Italy and G. Tovini Foundation for technical, economic and organisational support; NGO Dakupa for the collaboration in the research; Rotary Club Milano Sempione (Italy), Brescia municipality (Italy) and FCB Foundation (Brescia, Italy) for the economic support. Authors wish also to thank Marianna Bettinzoli, Eng. Chiara A.M. Clemente and Eng. Daniela Palazzini for the collaboration in the research projects.

\section{Author Contributions}

Luca Rondi carried out data collection and analysis and was responsible for the paper drafting; Sabrina Sorlini planned and supervised the research activities and the paper drafting; Maria Cristina Collivignarelli contributed to the research activities. All authors have read and approved the final manuscript.

\section{Conflicts of Interest}

The authors declare no conflict of interest.

\section{References}

1. UNICEF; World Health Organization. Progress on Sanitation and Drinking Water-2015 Update and MDG Assessment; WHO: Geneva, Switzerland; UNICEF: New York, NY, USA, 2015. 
2. Davison, A.; Howard, G.; Stevens, M.; Callan, P.; Fewtrell, L.; Deere, D.; Bartram, J. Water Safety Plan. Managing Drinking-Water Quality from Catchment to Consumer; Water, Sanitation and Health-Protection and the Human Environment: Geneva, Switzerland, 2005.

3. Etchie, A.T.; Etchie, T.O.; Adewuyi, G.O.; Krishnamurthi, K.; Devi, S.S.; Wate, S.R. Prioritizing hazardous pollutants in two Nigerian water supply schemes: A risk-based approach. Bull. World Health Organ. 2013, 91, 553-561.

4. World Commission on Environment and Development. Our Common Future-The Brundtland Report; United Nations: New York, NY, USA, 1987.

5. Mihelcic, J.; Crittenden, J.; Small, M.; Shonnard, D.; Hokanson, D.; Zhang, Q.; Chen, H.; Sorby, S.; James, V.; Sutherland, J.; et al. Sustainability science and engineering: The emergence of a new metadiscipline. Environ. Sci. Technol. 2003, 37, 5314-5324.

6. Klostermann, J.E.M.; Cramer, J. Social construction of sustainability in water companies in the Dutch coastal zone. J. Clean. Prod. 2007, 15, 1573-1584.

7. Jones, S.A.; Silva, C. A practical method to evaluate the sustainability of rural water and sanitation infrastructure systems in developing countries. Desalin 2009, 248, 500-509.

8. Malley, Z.J.U.; Taeb, M.; Matsumoto, T.; Takeya, H. Environmental sustainability and water availability: Analyses of the scarcity and improvement opportunities in the Usangu plain, Tanzania. Phys. Chem. Earth 2009, 34, 3-13.

9. Carter, R.C.; Tyrrel, S.F.; Howsam, P. The impact of sustainability of community water supply and sanitation programs in developing countries. J. Chart. Inst. Water Environ. Manag. 1999, 13, 292-296.

10. McConville, J.R.; Mihelcic, J.R. Adapting life-cycle thinking tools to evaluate project sustainability in international water and sanitation development work. Environ. Eng. Sci. 2007, 24, 937-948.

11. Montgomery, M.A.; Bartram, J.; Elimelech, M. Increasing functional sustainability of water and sanitation supplies in rural sub-Saharan Africa. Environ. Eng. Sci. 2009, 26, 1017-1023.

12. Katz, T.; Sara, J. Making Rural Water Supply Sustainable: Recommendations from a Global Study. In UNDP - World Bank Water and Sanitation Program; World Bank: Washington, DC, USA, 1998. Available online: http://www.its.caltech.edu/ e105/readings/rural_water.pdf (accessed on 6 March 2014).

13. Duncker, L. Hygiene awareness for rural areas in South Africa. In Proceedings of the 25th WEDC Conference Integrated Development for Water Supply and Sanitation, Addis Ababa, Ethiopia, 30 August-3 September 1999; pp. 79-81.

14. Hoko, Z.; Hertle, J. An evaluation of the sustainability of a rural water rehabilitation project in Zimbabwe. Phys. Chem. Earth 2006, 31, 699-706.

15. Schweitzer, R.W.; Mihelcic, J.R. Assessing sustainability of community management of rural water systems in the developing world. J. Water Sanit. Hyg. Dev. 2012, 2, 20-30.

16. Kwangware, J.; Mayo, A.; Hoko, Z. Sustainability of donor-funded rural water supply and sanitation projects in Mbire district, Zimbabwe. Phys. Chem. Earth 2014, 76-78, 134-139.

17. Dwivedi, A.K.; Bhadauria, S.S. Composite sustainable management index for rural water supply systems using the analytical hierarchy process. J. Perform. Constr. Facil. 2014, 28, 608-617. 
18. Schweitzer, R.; Grayson, C.; Lockwood, H. Mapping of Water, Sanitation, and Hygiene Sustainability Tools. Available online: http:/www.ircwash.org/sites/default/files/ triple-s_wp10mappingofwashsustainabilitytools.pdf (accessed on 8 July 2015).

19. Moriarty, P.; Batchelor, C.; Fonseca, C.; Klutse, A.; Naafs, A.; Nyarko, K.; Pezon, C.; Potter, A.; Reddy, R.; Snehalatha, M. Ladders for Assessing and Costing Water Service Delivery; IRC International Water and Sanitation Centre: The Hague, The Netherlands, 2011. Available online: http://www.ircwash.org/sites/default/files/Moriarty-2011-Ladders.pdf (accessed on 30 September 2013).

20. Netshiswinzhe, B. Strengthening sustainability of water supply projects. In Proceedings of the 26th WEDC Conference Water, Sanitation and Hygiene: Challenges of the Millennium, Dhaka, Bangladesh, 5-9 November 2000; pp. 336-339.

21. Kenel, P.P.; Schlaman, J.C. Preserving sustainable water supplies for future generations. J. Am. Water Works Assoc. 2005, 97, 78-92.

22. Gleitsmann, B.A.; Kroma, M.K.; Steenhuis, T. Analysis of a rural water supply project in three communities in Mali: Participation and sustainability. Nat. Resour. Forum 2007, 31, 142-150.

23. Esposto, S. The sustainability of applied technologies for water supply in developing countries. Technol. Soc. 2009, 31, 257-262.

24. Ujang, Z. Water Safety Plan: An Insight on New Pollutants, Water Chemistry and Sustainability. Available online: http://web.utm.my/vc-arc/images/keynote-water-safety-plan-10\%20nov2009.pdf (accessed on 6 March 2014).

25. Zurbrügg, C.; Gfrerer, M.; Ashadi, H.; Brenner, W.; Küper, D. Determinants of sustainability in solid waste management-The Gianyar waste recovery project in Indonesia. Waste Manag. 2012, $32,2126-2133$.

26. World Health Organisation. Guidelines for Drinking-water Quality, 4th ed.; World Health Organisation: Geneva, Switzerland, 2011; ISBN 978-92-4-154815-1.

27. Sorlini, S.; Palazzini, D.; Collivignarelli, C. Fluoride removal from drinking water in Senegal: Laboratory and pilot experimentation on bone char-based treatment. J. Water Sanit Hyg. Dev. 2011, 1, 213-223.

28. Sorlini, S.; Pedrazzani, R.; Palazzini, D.; Collivignarelli, M.C. Drinking Water Quality Change from Catchment to Consumer in the Rural Community of Patar (Senegal). Water Qual. Expo. Health 2013, 5, 75-83.

29. Bartram, J.; Corrales, L.; Davison, A.; Deere, D.; Drury, D.; Gordon, B.; Howard, G.; Rinehold, A.; Stevens, M. Water Safety Plan Manual: Step-by-Step Risk Management for Drinking-Water Suppliers; WHO: Geneva, Switzerland, 2009; ISBN 978-92-4-156263-8.

(C) 2015 by the authors; licensee MDPI, Basel, Switzerland. This article is an open access article distributed under the terms and conditions of the Creative Commons Attribution license (http://creativecommons.org/licenses/by/4.0/). 